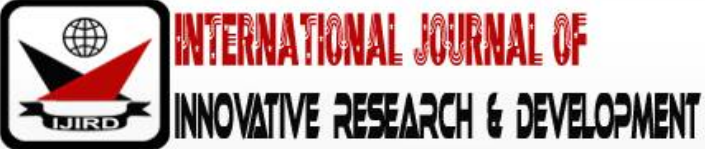

ISSN 2278 - 0211 (Online)

\section{Multiculturalism in Nigeria as a Factor in Promoting National Integration through Cross-Cultural Communication}

\author{
Barigbon Gbara Nsereka \\ Senior Lecturer, Department of Mass Communication, Rivers State University, Nigeria
}

\begin{abstract}
:
It is widely believed that Nigeria consists of a minimum of 250 ethnic groups with Hausa, Yoruba and Igbo as the three dominant ones. Each group has its own language and custom and accepts one or more of the main religions of Christianity, Islam and African traditional religion. This multi-ethnic, multi-cultural, multi-lingual and multi-religious nature of the country makes the pursuit of national unity, unity in diversity, a difficult task. And this is the background for the disruption and violence that have caused much of the displacement and internal migration in the country today. Whenever the parties to a communication act bring with them different experiential backgrounds that reflect a longstanding deposit of group experience, knowledge, and values, cross-cultural or intercultural communication is at play. This paper, therefore, explores the possibility of promoting national cohesion by means of cross-cultural communication in both its symbolic and linguistic forms. Concluding that if professionally applied, cross-cultural communication can enhance national integration, the paper recommends that Nigerians should understand cultural diversity, develop awareness of different cultures, and for this reason, introduce folkloristic ( the study of folklore) and cultural history in primary and secondary school curricula.
\end{abstract}

Keywords: National unity, promotion, cross-cultural communication, multiculturalism, folkloristic

\section{Introduction}

\subsection{The Nature of the Nigerian Society}

It is not quite certain how many ethnic groups Nigeria consists of but it is widely believed that Nigeria consists of a minimum of 250 ethnic groups- with Hausa, Yoruba and Igbo as the three dominant ones - and a maximum of 400 with over 400 different languages (Political Bureau Report, 1987; Awogbade, 2004). Each of the component groups has its own language and custom and accepts one or more of the main religions of Christianity, Islam and African traditional religion. Nigeria is, therefore, described as a multi-ethnic, multi-cultural, multi-lingual and multi-religious country - an apt description. Interestingly, this fact of our multiplicity is obvious, palpable, and stares us in the face. However, many a Nigerian sees the multiplicity of the nation- state more from a negative perspective than from the positive one. The multinatured status of the country which should have been hailed for being positively connected with diversity and variety (positive perspective) is being interpreted to mean difference and divergence (negative perspective). It is this negative notion of Nigeria's "multi" nature that the majority of our people seem to hold of the Nigerian society. That is, a great many Nigerians assume simplistically that the country would have been better off if it had been mono-cultural, and that multiculturalism is a burden and a curse of some sort.

Let us address this impression quickly before we proceed. First, it should be noted that some of the world's most prosperous cities, like London and New York, commit a sizeable part of their annual budgets to maintaining and even deepening their multiculturalism year after year (CNN, 2018). To be committed to deepening multiculturalism yearly, these cities must be reaping tangible benefits from their being multicultural. In spite of the 'troubles' that naturally come with being a multicultural human space, London and New York consistently remain high on the world live ability index ratings every year. AS CNN (2018) reported, "New York (and) London still sit within the highest tier of live ability, especially when contrasted with the worst-scoring locations.

Secondly, the assumption that multiculturalism is a burden and a curse should not be taken lightly at all. It is, in truth, a gangrenous substance that should not be left to fester. Such anti-multiculturalism disposition is the basis, the impetus, and the undercurrent for the intercultural violence we face in Nigeria today. For instance, many socio-political observers argue that many of the points raised by Biafra agitators to justify their discontent with the Nigerian experience are quite cogent, but whenever they refer to Hausas or Fulanis and sometimes to Yorub as in the disparaging ways that they sometimes do, it is that gangrenous anti-multicultural disposition that is at work. Similarly, it is argued that many of the accounts by the people of the North of Nigeria about why they should tread cautiously with the peoples of the South of Nigeria South are plausible, but whenever they derogatorily refer to South Easterners as yamiri, that is that gangrenous anti-multicultural disposition at play again. 
A country need not necessarily be culturally homogenous to be one country. There are at least two other countries of the world with more ethnicities, more cultures, more languages, and more religions than Nigeria and they both will rate higher than Nigeria in any national unity index rating. India, for instance, has over 2000 ethnic groups (US Department of State,2012 \& United States Library of Congress). China and India are reminders that being culturally, linguistically and religiously pluralistic is not in any way a life sentence to disunity. There are many benefits to being multicultural and many countries would wish they were as multi-culturally endowed as Nigeria. A multi-ethnic society, for instance, allows people to experience different ways of life, learn other people's languages, their arts, traditions and behavioural patterns. Multicultural education aims to prepare children for living in any multicultural society by making them understand different cultures. In the case of countries that unnaturally swell their populations by drawing cultural groups into their systems from all over the world through the offer of residency lotteries, immigrants are a source of diverse knowledge and experience. They can increase innovation, creativity and prosperity in our cities or countries. New residents also enrich the cultural base of countries by introducing new food, music, traditions, beliefs and interests.

The questions to answer then would be: How do multicultural countries deal with anti-multicultural sentiments, and how can Nigeria, multicultural country find its way around the intercultural violence it experiences, in order to achieve national unity? The answers seem to lie in effective cross-cultural communication, which is the thrust of this paper.

\subsection{Intercultural/ Cross-Cultural Communication: An Exposition}

Intercultural communication is the most abstract form of communication and yet the most pervasive. It is the "communication between members of different cultures (whether defined in terms of racial, ethnic or socioeconomic differences, or a combination of these differences)" (Tubbs \& Moss, 1987, p.17).

That is, it involves the interaction of different cultures, culture being a way of life developed and shared by a group of people and passed down from one generation to another. As it is probably well known, culture conditions such things as the food we eat, the kind of shelter we choose, the clothes we wear and the language we use. "Whenever the parties (to) a communication act brings with them different experiential backgrounds that reflect a longstanding deposit of group experience, knowledge, and values, we have intercultural communications" (Samovar \& Porter, 1998, p.21).

This dimension of experience cuts across all communication contexts: it may occur in a two-person, small group or any other type of communication. Hence, the observation that it is most pervasive. As for its description as abstract, it is so (i.e. abstract) because the communicator could be exchanging cultural values (based on his background and experience) with another communicator without either of them knowing.

Scholars often interchange cross-cultural communication with intercultural communication. Much as it would not be wrong to use both terms interchangeably, the razor-sharp- thin line of distinction between the two concepts is useful to establish here. A helpful treatment is provided byJun Xu (2011), a Chinese scholar at the English Language Department of Dezhou University, Shandong, China. Under the heading of "Defining Intercultural Communication and Cross-Cultural Communication", Xu (2011) provides the following clarification:

The most intercultural communication may be between identical twins, then fraternal twins, followed by brothers and sisters. If the twins meet twins from a different culture and converse and interact, whether unintentionally or purposefully, then intercultural communication occurs as in the presence of another... When researchers want to compare or contrast how the twins from different cultures interact interculturally, then a cross-cultural communication study occurs (p. 884)

Xumakes his distinction between the terms on a comparing and contrasting as is. His metaphor of identical twins, fraternal twins, and brothers and sisters is most apt. Putting Xu differently, if the culture of the interact ants were as similar as identical twins; communication between such interact ants would be more intercultural than if their cultures were as similar as un-identical twins. In same vein, if the interact ants' cultures were as similar as un-identical twins, their communication would be more intercultural than if their cultures were as similar as brothers and sisters who were not twins. Xu's point is that the more comparable the cultures of the interact ants, the more he would rather define their communication as intercultural; and the more contrastable their cultures, the more he would define their communication as cross-cultural. This is a keen point about cross-cultural communication. While intercultural communication is communicating from available bases of commonality, cross-cultural communication is communicating in spite of obvious un-commonality.

It is reasonable to agree with $\mathrm{Xu}$ that all communication is both intercultural and cross-cultural. However, communication within the Yoruba nation is more intercultural than cross-cultural, while communication between the Yoruba nation and the Ibo nation is more cross-cultural than intercultural. This informs our choice of cross-cultural communication, not intercultural communication, in this work, to promote national unity. That is to say, cross-cultural communication involves more diverse groups than intercultural communication. For instance, the communication between the Ijebu people of Ogun State and the Oyo people of Oyo State is both intercultural and cross-cultural, with the degree of intercultural interaction between them being higher than that of cross-cultural interaction. However, communication between the Ijebu people of Ogun State and the Ngwa people of Abia State is more cross-cultural than intercultural. This is why this paper feels that welding the peoples of Nigeria together requires more of cross-cultural communication than intercultural communication.

Building bridges across wide gaps is the forte of cross-cultural communication. It is predicated upon mutuality, respect, and acceptance. Xu (2011) posits that intercultural communication takes place more in interpersonal interaction while cross-cultural communication occurs more in group communication. 


\subsection{Origins, Migrations and Settlements of Nigerian Peoples: The Need to Be One}

Although controversies, claims and counter-claims characterise the traditions of origins and migrations of the different Nigerian peoples, it is important to note that certain areas of Nigeria such as the Upper Benue Valley, the NigerBenue Confluence, and the Central Highlands of the Middle Belt were centres of origin or parent stocks from which many groups in Nigeria branched out to their present abode (Political Bureau Report, 1987). Even more significant was the fact that in the course of their migrations, many groups came into contact with one another and through such processes as intermarriages, settlements, however temporary, and mutual cultural borrowings, began to impact on one another.

In many significant ways, the institutions and cultures which eventually developed in the Nigerian region in the pre-colonial period were the end products of long processes of accommodation and fusion of different strands brought in by different migratory groups. Thus, although some ethnic purists and chauvinists would emphasise the distinctness of the cultures of the different people of Nigeria, the historical evidence points to greater intermingling, interdependence, mutual accommodation, and tolerance of the groups. This, of course, is not to deny that frictions and conflicts occasionally erupted over such matters as land and trade routes.

The point to stress, however, is that Nigerians of this formative period were tolerant and accommodating to one another. This disposition was facilitated by the similarities in the fundamentals of the cultures of the groups who derived mainly from "a basic African agricultural civilisation". Indeed, in many critical ways, many of today's ethnic groups in Nigeria are products of coalescence and accommodation with one or more of the original migrant groups, although each group has tried to maintain its identity. Historically speaking, therefore, the ethnic groups in Nigeria today (which ironically constitute a major drawback to true national unity), are products of history, representing groups that emerged as a result of deliberate acts of statesmanship and social engineering (Political Bureau Report, 1987).

The traditional political systems of the groups are usually classified into two broad categories as follows:

- The centralized governmental systems varying from relatively small chiefdoms to very large states;

- The non-centralized political systems.

The political systems of the Hausa/ Fulani, the Kanuri, Yoruba and Edo are usually classified as large centralized systems with varying degrees of complexity and territorial spread. The Igbo, Ibibio/ Efik, Tiv, Ekoi and many other groups in the middle belt, had small, fragmented political systems. The Hausa/ Fulani, Yoruba, and Igbo who are numerically dominant in the northern, south-western and south-eastern sections of the country respectively, are usually referred to as the majority ethnic groups while the small groups in all sections are lumped together as minority ethnic groups.

\section{Cross-Cultural Communication in Promoting National Integration}

In this section, we will discuss the workings of cross-cultural communication and how it can help the diverse peoples or ethnic groups of Nigeria "stretch" towards national unity. "Stretch" is a word and idea that is closely related to cross-cultural communication. It is with and by cross-cultural communication that a people stretch to reach across cultural boundaries, stretch to reach across dividing cultural lines, stretch to reach across cultural 'dissimilarities'.

A first approach to stretching towards national unity is with food, dress, and all other such items of material culture. Oloidi (2005) rightly notes that "dressing is [a] source of diversity in the Nigerian cultural experience" (p. 93) and "cultural experiences also echo among groups in their diet" (p.92). By "stretching towards national unity with food and dress' we mean that ethnic/ tribal food or dress cultures be freely adopted across cultures until they pass for national culture. In this regard, Nigerians have not done poorly. Afang soup, a delicacy which has its roots in the Efik-Ibibio-OronAbak cultures of old Cross River State, has been so widely adopted that it now passes for national food culture. Aseobi, a Yoruba/ Southwestern festive dress culture, now passes for Nigerian culture. Same for Kaftan, a Northern Nigerian dress style, now adopted nationally. Adopting them across cultures until they pass for national culture is a powerful gestural communication approach for giving all cultures in the country a shared sense of acceptance and mutual respect. In lifting dress (kaftan, babariga, resource control, aseoke, aseobi), food, and all the other fabrics from clannish connotations to being national artefacts, Nigerians are not doing badly.

Understanding the folklore of Nigerians cross-culturally can help promote national integration. The culture of a people is usually reflected in its folklore. Folklore is the traditional art, literature, knowledge, and practice that is disseminated largely through oral communication and behavioural patterns. Every group with a sense of its own identity shares, as a central part of that identity, folk traditions-the things that people traditionally believe (planting practices, family traditions, and other elements of worldview), do (dance, make music, sew clothing), know (how to build an irrigation dam, how to nurse an ailment, how to prepare barbecue), make (architecture, art, craft), and say (personal experience stories, riddles, song lyrics) (http: / / www.afsnet.org/ ?page=What Is Folklore, p.1).

Folklore deals with the beliefs, traditions, experiences and superstitions of a people transmitted from generation to generation through oral tradition (Nwanne, 2006). Essentially, folklore worries about how the cultural norms of a people are transmitted from parents to their children. This is important in the traditional African communication, which has remained largely oral. Folklore comprises prose narratives such as legends, folktales, myths and fables.

Folklore is an integral part of any culture. In the olden days, elders gathered young ones, especially children, to tell them stories of dead people that had shown bravery, of animal kingdom, birds, reptiles, and the gins. Those stories (folktales) have the capacity to sensitize children to the immediate environment; help children develop self-confidence; sharpen the children's survival instinct; increase the children's patriotic activities; and enhance their moral development.

Reinforcing the observance of national emblems like the Nigerian flag and the consistent recitation of the National Pledge and singing of the National Anthem will stretch towards national unity. 


\section{Patriotism and Fidelity as Factors in Cross-Cultural Communication}

Patriotism, as defined by Word Web Dictionary, is the love of one's country and the willingness to sacrifice for it. Patriotism, also called national pride, is the ideology of love and devotion to a homeland, and a sense of alliance with other citizens who share the same values. For the Simple English Wikipedia, the free encyclopaedia, patriotism means "loyalty of person to his/ her own nation or the leaders of (the) nation."

According to Nwanze (2008), on the eve of July 4, the anniversary of the American Independence, the flag bearers of both the Republican Party and the Democratic Party for the November 2008 presidential elections, Senator John McCain and Senator Barak Obama respectively delivered their speeches to commemorate the event. Both candidates interestingly dwelt on the notions of patriotism. For McCain,

...to love one's country is to love one's countrymen. If we are to replicate the spirit of our founding age, if we are to be genuine patriots, we must remember also that we are patriots, we must remember also that we are patriots because we love the countrymen we will never know, who will be born after we are gone (quoted in Nwanze, 2008, pp. 181-182).

McCain's conception of patriotism is four-fold, namely:

- That patriotism is putting the nation first ahead of self and any other consideration;

- That patriotism is selfless service to the nation;

- That the love of one's country, like all love, is a two-way traffic: your country loves you, you love your country; and

- That a major component of patriotism is that you love your fellow countrymen and accept them.

This position of McCain reflects that of the great Thomas Jefferson who once said:

With earnest prayers to all my friends, to cherish mutual goodwill, to promote harmony and conciliation, and above all things to let the love of our country soar above all minor passions, I tender you the assurance of my affectionate esteem and respect (quoted in Nwanze, 2008, p.182).

For McCain's Democratic Party rival, Barak Obama, true patriotism sometimes demands dissent. In his words: We may hope that our leaders and our governments stand up for our ideals, and there are many times in our history when that's occurred.... but when our laws, our leaders or our government are out of alignment with our ideals, then the dissent of ordinary American may prove to be one of the truest expressions of patriotism (quoted in Nwanze, 2008, p. 182).

Senator Obama, considered by some as an insurgent because of his message of change, here echoes Mark Twain who once said "Patriotism is supporting your country all the time and your government when it deserves." This idea is amplified by Robert Lee who is of the same frame of thought when he explained that: "true patriotism sometimes requires of men to act exactly contrary, at one period, to that which it does at another, and the motive which impels them, the desire to do right, is precisely the same" (quoted in Nwanze, 2008, p. 183).

There are extreme forms of patriotism, a notable one of which was attributed to Carl Schulz in that famous expression: "My country, right or wrong." Still on patriotism Indira Gandhi was quoted as saying: "We would rather starve than sell our national honour."

If one is patriotic, one would be ready to communicate with other Nigerians with the deep consciousness that one is communicating with a Nigerian, no matter the ethnic group that the communicatee belongs to. That Nigerianness in the psyche of the interactant is what should guide the cross-cultural interaction among Nigerians. Having the consciousness of being a Nigerian does not take away one's ethnic identity, nor should being an Igbo, Yoruba or Hausa endanger one's identity as a Nigerian. Communicating cross-culturally, therefore, should be guided more by the appreciation of our multiculturalism than by ethnic sentiments.

Another important factor in cross-cultural communication is that of fidelity of communication. According to Agba (n.d.), a communicator hopes that his communication will have a high fidelity. By fidelity is meant the accuracy of communication (i.e. absence of any loss of meaning). A high-fidelity decoder is one that translates a message for the receiver with complete accuracy. There are at least four factors within the source-encoder, which can increase fidelity of communication. With regard to cross-cultural communication among Nigerians, these factors as stated below are very important:

- Communication skills

- Attitude

- Knowledge level

- Position within a socio-cultural system

\subsection{Communication Skills}

As we are aware, there are five verbal communication skills. Two of these, writing and speaking, are encoding skills or expressive communication while two of them, reading and listening, are decoding skills or receptive communication. The fifth, which is crucial to both encoding and decoding, is thought or reasoning.

To encode a message, which expresses a purpose (communication is necessarily purposeful), Nigerians need to possess the necessary encoding and decoding skills in order to facilitate mutual cultural exchange. If we are to write our message, we need to have a vocabulary adequate to express our ideas clearly. Our expressive communication, whether formally or informally, should be handled with respect for one another's culture. 


\subsection{Attitude}

The attitude of a communication source affects the way in which he or she communicates. The source's attitude can be categorized into three, namely: (i) attitude towards self (ii) attitude towards subject matter and (iii) attitude towards the audience.

\subsubsection{Attitude towards Self}

Attitude towards self is either negative or positive. Negative attitude towards self-manifests itself in lack of selfconfidence. The Nigerian does not need to lose self-confidence because he or she lacks of understanding of the other person's language, for instance. Self-abasement can adversely affect fidelity of communication in cross-cultural or even intercultural discourses. Positive attitude towards self-engenders self-confidence and enhances fidelity of communication.

\subsubsection{Attitude towards Subject Matter}

Attitude towards subject matter affects the source's communication behaviour. If a communicator does not believe in the value of his subject matter, say a message on national unity, it is difficult for him or her to communicate it effectively. Here comes the necessity to learn one another's language, as language is a unifying factor. This can explain why the Hausa suya seller by the roadside is more receptive of, and therefore kinder to, the buyer (Igbo, Yoruba or Ijaw) who speaks his language.

\subsubsection{Attitude towards the Audience}

A third kind of attitude which affects the source's communication behaviour is his attitude towards the receiver of his message, the other fellow in the communication process. When audience members realize that the writer or speaker really likes them, they are much less critical of his messages, and much more likely to accept what he says. When a Nigerian from one cultural background communicates with another from another cultural background with love, respect for and acceptance of the communicatee's cultural peculiarities, communication is likely to be effective. Aristotle called this perceived characteristic of the speaker ethos, i.e. a quality in the speaker that is personally appealing to the listener. Aristotle identifies three qualities that build high source credibility as intelligence, character and goodwill (Agba, n.d.).

\subsection{Knowledge Level}

It is obvious that the amount of knowledge a source has about his subject matter will affect his message. One cannot communicate what one does not understand. Except one has adequate knowledge of the benefits of national unity and multicultural cohesion, and is passionate about it, one may not be very successful in advocating national integration. A properly trained communicator understands the social importance of the role he has undertaken and also knows what he wants to communicate as his message. He understands the characteristics of his audience and studies the varying interests and understanding levels of groups of people who make up the audience. He moulds his message to the capabilities of the audience type he is trying to reach.

\subsection{Social System}

A source's position in a socio-cultural context will affect his general communication behaviour. People in differing social classes communicate differently. A spokesperson for an ethnic group, who is a more mature communicator, will certainly get the message across better than an untrained speaker who may be guilty of hate speech. Social and cultural systems partly determine the word choices which people make, the purposes they have for communicating, the meanings they attach to certain words, their choice of receivers, and the channels they use for this or that kind of message.

\section{Challenges of Cross-Cultural Communication in the Promotion of National Cohesion}

The challenges of cross-cultural communication as adduced by this paper are communicational, psychological and geographic. On the communicational front, the challenges are basically factors that hamper effective cross-cultural communication, that is, barriers to effective communication. Effective communication, we do know, is that which achieves its goals. According to Agba and Okoro (1995), communication is effective when "what is said is what is meant (intended) and what is meant is what is understood and what is understood is what is done and what is done is the desired action" (p. 2). Olugbenga (n.d.) in a workshop paper entitled: "Basic Communication Skills for Effective Election Monitoring" identified these barriers as perceptual processes, attribution process and semantics, and discussed them as follows:

\subsection{Perceptual Processes}

\subsubsection{Perception}

This is the mental process by which individuals acquire and make sense out of information available to them. This process involves three stages:

Selecting: the filtering of stimuli that we encounter so that only certain information receives our attention; (b) Organising: the patterning of information from selection stage; and (c) Interpreting: attaching meaning to the information that we have selected and organized. The perception of an individual is affected by a variety of factors such as experiences, needs, personality, culture and education. 


\subsubsection{Stereotyping}

Stereotypes are perceptions or beliefs that people hold about groups or individuals based on previously formed opinions and attitudes. Stereotyping is, therefore, "the tendency to attribute characteristics to an individual on the basis of an assessment of the group to which the individual belongs" (Olugbenga, n.d; p.2). This may lead often to wrong conclusions about the characteristics of the individual, rather than the message being passed. An example is the mistrusting of an honest Igbo friend because of the general public impression of Igbo people as being very greedy or dishonest in monetary matters. Such a sentiment is offensive to the affected people and so undermines the efficacy of cross-cultural communication.

Given the volatile nature of stereotyping, we need to know about the subject. Nwagbara (2013) writes that stereotype as a concept has its origin in psychology, adding that 'it is derived from the Greek wordstereos, which means 'firm' or 'solid' and typos, which means 'impression', hence the idea of 'solid impression'" (p.252). Continuing, Nwagbara (2013) recalls that:

Psychologists who first worked in this area (of stereotyping) set out to determine the origins of attitudes. But as they progressed in their search, their interest became rather diverted to how attitudes change and why some seem more resistant to change than others. Stereotypes were then seen as an exceptional type of attitude - one that was particularly difficult to change. Thus, stereotypes became associated with some form of "blinkered" mental attitude (Barrat, 1986)" (p.253).

In Nigeria, the stereotypes that people hold about the three dominant ethnic groups is that the Hausa are violent and dagger-wielding; the Yoruba are terribly tribal and the Igbo are money-mongers. Whether particular stereotypes hold any water or not is determined by time. In cross-cultural communication towards national cohesion, stereotypes are to be deliberately downplayed.

\subsubsection{Halo Effect}

The tendency to use a general impression based on one or a few characteristics of an individual to judge other characteristics of that same individual. For example, a rater may use a poor performance of an individual on a text to rate other performances (even if they are excellent) of that individual.

\subsubsection{Projection}

The tendency of an individual to assume that others share his or her thoughts, feelings, and characteristics. This is more of a one-way communication because we assume that we know how others feel on various issues.

\subsubsection{Perceptual Defence}

The tendency to block out or distort information that one finds threatening or that challenges one's beliefs. This may lead to individuals not being receptive to certain types of information, a situation called "shoot the bearer of bad news" syndrome.

Perceptual processes such as described above are a challenge to cross-cultural communication as they can to withholding information or giving too little information in during cross-cultural interactions.

\subsection{Attribution Process}

\subsubsection{Attribution}

This is an attempt to explain how individuals make judgements or attributions about the causes of another's or their own behaviour. Such judgements often form the basis for subsequent actions. With the school of thought, we may make causal judgements that are either dispositional (attributed to internal causes, such as personality traits or a person's own effort) or situational (attributed to external causes, such as equipment or luck).

\subsubsection{Fundamental Attribution Error}

The tendency to underestimate the importance of situational influences and to overestimate the importance of dispositional influences in explaining the behaviour of others.

\subsubsection{Self-Serving Bias}

The tendency to perceive oneself as responsible for successes and others as responsible for failures. This tendency sets the stage for serious communication problems between individuals because each actor sees himself as the yardstick for success and others as the cause of failure.

\subsection{Semantics}

Words are symbols; therefore, they do not necessarily have the same meaning to everyone.

\subsubsection{Semantic Nets}

The network of words and word meanings that an individual has available for recall. Each individual has his or her semantic net, which overlaps, but does not correspond exactly with the nets of others. 


\subsubsection{Semantic Blocks}

The blockages or communication difficulties that arise from word choices. Such blocks are common place because various meanings and shades of meanings that individuals attach to words depend on each person's semantic net. Receivers decode words and phrases in conformity with their own semantic networks, which may be very different from those of the senders.

Again, attribution processes of attribution, fundamental error and self-serving bias as well as semantic nets and blocks are challenges to cross-cultural communication as they can unduly attribute failures and wrong choice of words to Nigerians from cultures other than one's own and so cause offences during cross-cultural interactions.

The geographic challenge to cross-cultural communication is in the area of the size of the country in terms of population and territory as well as in the area of displacement and internal migration occasioned by religiously, politically, ethnically or cultically orchestrated violence and killings as we experience on a daily basis in the country today.

According to the latest United Nations estimates elaborated by World ometres, the current population of Nigeria is well over 197 million, which is equivalent to $2.57 \%$ of the total world population. Nigeria ranks number 7 in the list of countries (and dependencies) by population. The population density of Nigeria is 215 per $\mathrm{Km}^{2}$ (i.e.557 people per mile 2 ). The total land area is $910,770 \mathrm{Km}^{2}$ (351,650 miles2). This figure contradicts the 927, 768 square kilometres which was supplied as Nigeria's land area by the Political Bureau Report of 1987, a well-researched document by Nigeria's best brains at the time. Geographers classify the country into two broad zones, namely, the tropical rain forest zone which stretches from the coast to about 90latitude and a savannah zone which covers the rest of the country, up to the Nigeria/ Niger boundary (Political Bureau Report, 1987).

Although early in this work it has been argued that Nigeria's multiplicity of cultures, languages, ethnic nationalities and religions is not a curse, it is not unreasonable to state that it is too unwieldy to manage without sentiments - good, bad and ugly - here and there, especially if the political leadership is undisciplined, myopic and chauvinistic. Herein is the foundation of the raging argument against our being together as a country. Yet this paper believes that we are more diverse than different peoples and can find our way around all the apparent differences.

Psychologically, cross-cultural communication is difficult where legitimate citizens of Nigeria have been displaced from their original homes by internal pogroms and are now either living in the camps of internally displaced persons (IDPs) or elsewhere.

\section{Conclusion and Recommendations}

If professionally applied, cross-cultural communication can enhance national integration, especially with the enablement of a people-centred government that listens to the voice of reason and is willing to see Nigeria as one. Accordingly, political leaders who publicly claim to be running a Nigerian government but are practically servicing only ethnic interests and lacking the political will and courage to combat insecurity, thereby perpetuating the cause of displacement and internal migration and making cross-cultural communication ineffective, must rethink. Secondly, Nigerians should understand cultural diversity and develop awareness of different cultures to be able to bear one another's frailties and enjoy one another's strengths. For this reason, education authorities should introduce folkloristics (the study of folklore) and cultural history in primary and secondary school curricula.

\section{References}

i. Agba, P.C. \&Okoro, M.N. (1995). Fundamentals of graphic communication. Enugu: ACENA Publishers.

ii. Agba, P.C. (n.d.) Lecture notes, Department of Mass Communication, University of Nigeria, Nsukka.

iii. Awogbade, M. (2004). Ethnography of Nigeria. Abuja: National Open University of Nigeria.

iv. CNN(2018). The world's most liveable cities in 2018, https:// edition.cnn.com/travel/article/ worlds-mostliveable-cities-2018/index.html

v. Nwagbara, G. (2013). Culture, stereotypes and information processing. In U. Pate; C. Nwabueze; \& N. Idiong (eds.). Politics, culture and the media in Nigeria (251-260). Ibadan: Stirling-Horden Publishers Ltd

vi. Nwanze, I. (2005). Random reflections. Port Harcourt: Heroes and Legends Ltd.

vii. Oloidi, F.J. (2005). Unity in diversity: The Nigerian experience in ethnic relations. In F. Anyika (Ed.). African humanities: Humanities and nation building (pp. 89-110). Nsukka: Afro-Orbis Publications Ltd

viii. Olugbenga, A. (n.d.). Basic Communication skills for effective election monitoring. Workshop paper(n.p.).

ix. Political Bureau Report (1987). Reproduced for mass distribution by the Directorate for Social Mobilisation. Abuja: MAMSER

x. Samovar, L.A.\& Porter, R.E. (1998). Communication between cultures. Belmont: Wadsworth.

xi. Tubs, S.L. \& Moss, S. (1987). Human communication. New York: McGraw-Hill Inc.

xii. US Department of State (2012). Background Note: India. Archived from the original on 18 June 2012.

xiii. Xu, J. (2011). Brief Analysis on Cross-cultural Communication. Theory and Practice in Language Studies, 1 (7), 884-887. 